\title{
『傷寒雜病論』對脾胃學說的貢獻
}

\author{
辽宁中医药大学附属医院 ${ }^{1} \cdot$ 圓光Digital大學 醫史文獻研究所 ${ }^{2}$ \\ 王垂杰 $^{1} \cdot$ 金曉哲 $^{2 *}$
}

\section{The contribution of Treatiseon Febrile Diseases and midcellaneous diseases(伤寒杂病论) to the theory of spleen and stomach}

\author{
Wang Chui-jie ${ }^{1} \cdot$ Kim Hyo-chul ${ }^{2^{*}}$ \\ ${ }^{1}$ Liaoning University of Traditional Chinese Medicine \\ ${ }^{2}$ Institute of Medical History and Medical Literature, Wonkwang Digital University
}

Objective : The main topic of this study is how the contribution of Treatiseon Febrile Diseases and midcellaneous diseases written by Zhang Zhonging(张仲景) to the theory of spleen and stomach has been.

Method : Analysis of formula in Treatiseon Febrile Diseases and midcellaneous diseases with theoretical and historical perspectives is the main method of the study.

Result : The theory of spleen and stomach, which is formed in the long term medical practice, is the important component theory of traditional Chinese medicine. Zhang Zhongjing made a great contribution to the theory of spleen and stomach from disease prevention, the contraindication, drug usage, aftercare and so on in Treatiseon Febrile Diseases and midcellaneous diseases, which fully shows the academic ideals of strengthening spleen and stomach.

Conclusion : Helping to study Treatiseon Febrile Diseases and midcellaneous diseases and understand the thought of Zhang Zhonging, and gives reference to the theory of spleen and stomach' research in Treatiseon Febrile Diseases and midcellaneous diseases.

Key words : the theory of spleen and stomach, febrile disease, Synopsis of the Golden Chamber

\section{I . 序 論}

* 교신저자 : 金晓哲, 圓光Digital大學 醫史文獻研究所, E-mail : somagim@hanmail.net Tel : 070-7730-0091 접수일(2012년 10월 25일), 수정일(2012년 11월 14일), 게재확정일(2012년 11월 20일).
脾胃学说是中医整个学术体系的精华部分之一。从 脾胃学说理论的提出, 到发展形成系统的理论, 经历了 一个漫长的历史过程。在这个历史进程中, 它不断地发 展完善，且不断地应用于临床，指导着临床。同时也在 临床中得到验证, 证明了其科学性。『伤寒论杂病论』以 
脾胃为本的思想在辨证论治与理法方药方面对中医脾胃 学说形成和完善起到了承前启后作用, 仲景以脾胃为本 的学术思想不仅将『内经』确立的脾胃理论创造性地应用 于临床实践, 而且开后世李东垣的温阳升脾说, 叶天土 的滋阴降胃说和李中梓的脾为后天之本说等先河, 对中 医脾胃学说形成和完善起到了承前启后作用 1 )。其对脾 胃学说的发展主要贡献体现在以下几个方面。

\section{II. 本 論 \\ 1. 强调实脾在疾病防治中的作用}

治未病，就是预防疾病的发生和发展，防患于未 然2)。『素问·四气调神大论』提出: “圣人不治已病治未 病”3)，张仲景依据『黄帝内经』“脾治中央，常以四时长 四藏, 各以十八日寄治不得独主于时也。”(『素问·太阴 阳明论』及有爷五脏病传变的论述, 首先提出临床治疗 应当实脾的主张, 指出“夫治未病者, 见肝之病, 知肝 传脾，当先实脾”4)即“四季脾旺不受邪”5)。根本大法， 文中以治肝实脾为例, 实为强调在疾病即将发生传变的 爸键时机, 调补脾胃是很有意义。认为只有脾气充旺才 能心肝肺肾之气俱旺, 反之脾胃气一伤百病丛生, 这一 观点作为脾胃学说之先河也受到了历代医家的重视。

\section{2. 脾胃病证的辨证论治方面}

『黄帝内经』以经络、脏腑作为病证辨治纲领的思 想, 在『伤寒杂病论』中得到充分的继承和发扬, 具体辨 证方法可有如下几方面的途径。

\section{1）六经传变，脾胃为枢}

六经传变虽与病邪轻重、正气强弱以及治疗调护是 否得当等因素有䏌，但总以胃气盛衰为前提，即脾胃虚 弱是导致疾病发生、发展和传变的重要因素。一般而

1）黄贵华. 张仲景脾胃学说研究概况. 广西中医学院学报. 2006. 9(4). pp.70-72.

2) 丁文君, 张瀚元, 王柳明. 『金匾要略」治未病之管窥. 吉林中医 药. 2009. 29(3). pp.269-270.

3）孙国中, 方向红(校注). 重广补注黄帝内经素问. 北京. 学苑出 版社. 2004. p.19.

4）陈纪藩. 金贾要略. 北京. 人民卫生出版社. 2000. p.36.

5）陈纪藩. 金贵要略. 北京. 人民卫生出版社. 2000. p.36.
言，脾胃气弱，邪气盛，则病邪由表及里，由浅入深而 病进; 若脾胃气强, 抗邪外出, 由里出表则病退。从三 阳经传变看，太阳病失治误治，损伤中阳，可导致诸般 变证，如“发汗后，腹胀满者，厚朴生姜牛夏甘草人参 汤主之。” ${ }^{6}$ ，为太阳病过汗损伤脾阳，或素体脾虚、 再发汗不当，脾阳更伤，而致腹满证。“伤寒，若吐若 下后，心下逆满，气上冲胸，起则头眩，脉沉紧……获 苓桂枝白术甘草汤主之。” 7)为伤寒误用吐下损伤脾 胃，致水饮上逆证。更有因误下损伤脾胃，而致寒热错 杂、虚实互见、升降失调的泻心汤证。而且太阳病可传 变形成阳明病，如太阳病汗下太过伤津，约束脾阴之转 输, 则成脾约证8)。同样若少阳病误用汗、吐、下法, 损伤胃津，可致邪入阳明，如“少阳不可发汗，发汗则 垥语，此属胃，胃和则愈，胃不和则烦而拝。”9)，说 明少阳病因发汗伤胃阴，转属阳明之病。从三阳病向三 阴病传变看，脾胃功能亦尤为爸键，如“伤寒三日，三 阳为尽，三阴当受邪，其人反能食而不呕，此为三阴不 受邪也。”10)，其“能食而不呕”正说明脾胃功能健旺， 脾胃气和，自可不传三阴。反之说明，脾胃虚弱，邪气 可乘虚内陷，传入三阴。再从三阴经传变论看，三阴病 以脾胃气损为始, 脾胃气损为进, 亦以脾胃气绝为危, 脾胃气复为转机。太阴病为脾阳虚弱，寒湿困滞，由于 中阳不足，多可损及心肾，导致心肾阳虚，而转成少阴 证。如“少阴病，欲吐不吐，心烦，但欲宊，五六日自 利……，属少阴也。”11)此因胃中空虚，阳气困扰，故 “欲吐不吐。”而若脾虚失运，土虚木郁，肝气横逆，犯 胃乘脾，则又可形成寒热错杂的榞阴病。

\section{2）治则制方，法重脾胃}

在六经病的辨证论治中，仲景从理、法到方药，处 处以脾胃为本，其养胃扶正以社邪及祛邪不伤脾胃的思 想贯穿其中, 诸般治法均无损脾胃。例如在『伤寒论』 113 方中(缺禹余粮丸一方)，用甘草的有70方，用姜的 有63方(其中生姜39方，干姜24方)，用大霑的有40

6）熊曼其. 伤寒论. 北京. 人民卫生出版社. 2000. p.162.

7) 熊曼琪. 伤寒论. 北京. 人民卫生出版社. 2000. p.16.

8）熊曼琪. 伤寒论. 北京. 人民卫生出版社. 2000. p.444.

9）熊曼其. 伤寒论. 北京. 人民卫生出版社. 2000. p.533.

10）熊曼琪. 伤寒论. 北京. 人民卫生出版社. 2000. p.539.

11）熊曼琪. 伤寒论. 北京. 人民卫生出版社. 2000. p.556. 
方，用人参的有 22 方，用白术的有 10 方。选用这些药 物, 多是用它的补谷脾胃, 益气生津, 调中养胃, 顾护 脾胃的作用, 以防止脾胃受损, 杜绝病情的演变。

\section{（1）发汗解表，必资化源}

汗法，令邪气藉汗而散，然汗为津液所化，胃为津 液之腑，若欲藉汗驱在表之邪，必滋化源。故仲景立桂 枝汤外调营卫, 内和脾胃, 从脾胃以达营卫。方中不仅 以采甘草、生姜、大東补谷脾胃, 而且要求药后啜热稀 弹了, 助胃气益津液, 以滋酿汗之源; 麻黄汤虽峻汗, 但 配伍多甘草，旨在汗不伤正。五苓散可通阳和表、化气 行水, 其立足点也以健运脾阳为主。

（2）清热攻下, 保存胃阴

阳明病热结，治当清下，但仲景在祛邪时，常兼顾 胃气。如白虎汤证，方中既以知母、石膏之大寒清其邪 热，又以粳米、甘草盆气以调和中气。仲景立承气之 法，承顺胃气，荡涤燥结，一则恢复胃气和降，二则急 下存阴. 既可下其燥结，又无伤阴之虞，一投两效。

\section{（3）扶助正气，和解托邪}

少阳病邪在牛表牛里，胆胃失和，邪正交争，虚实 相夈，治宜扶正达邪外解，拟方小柴胡汤。其中扶正主 要是补益脾胃, 复振中气. 故方中除用柴胡、黄芩、牛 夏和解少阳外，人参、大束、生姜、甘草等皆为补中和 胃之品。即所谓“少阳主治，全赖胃气充满。”其用参、 草补中者，以少阳气弱血尽，全赖中土滋养，则木气始 得荣发, 即是胃和则病愈之义。仲景所谓“胃气因和, 身㵊然汗出而解。”正道出了小柴胡汤作用的底蕴。

\section{（4）温扶阳气，补土保元}

三阴之病，阳气虚弱，治当温阳。仲景治疗三阴虚 寒之证, 温阳时总以补益中焦为宗旨。如太阴病主方理 中汤, 功在温运脾阳, 散寒除湿, 属温补中土的第一 方。温中补虚除四逆汤、理中汤外，尚有小建中汤，其 合甘温、辛甘、酸甘为一方，具有温养中气、平补阴 阳、健运脾胃、调和营卫之功。『伤寒论』以脾胃为中 心，执中州以灌四旁，用小建中汤健运中气，化生气 血，则阴阳自和，脏腑得安而病愈。少阴病四逆汤为脾
肾之阳同健的温补脾肾方，仲景以之治少阴病，寓复中 阳而救肾阳之旨。厥阴病之乌梅丸以温热入脾胃之药尤 多, 且以蜜作丸, 资助胃气，以防重伤脾胃。全方寒温 并用，土木两调，在温扶阳气的同时，补益中焦，以强 健后天之本，从而增强治疗效果。仲景对三阴病的证治 方法，显示了其治疗宗旨为恢复脾胃之气。

（5）辛开苦降，升降脾胃

六经病过程中，有诸多变证多是寒热错杂，或升降 反作，诸如㾂证、寒格等。故仲景治疗时皆从调理脾胃 气机升降着手，例如三个泻心汤、黄连汤、干姜黄芩黄 连人参汤、旋覆代赭石汤等，皆以辛开苦降之药，伍以 培补中气、健运脾胃的人参、大東、生姜类，盖以脾宜 升则健，胃宜降则和，脾胃调和，则升降枢机如常，寒 热自可调和。

\section{3）提出治禁，源于护胃}

仲景在论中會反复多次论述误用汗、吐、下或汗、 吐、下太过所引起的各种不良后果，旨在强调顾护脾 胃，把社邪而不伤正作为治病的准则。其所论变证，对 于只知攻邪而不顾脾胃者，当引以为戒。例如“凡用秨 子汤，病人旧微溏者，不可与服云。”12)示人治热扰胸 膈证，若素脾胃虚寒而大便溏薄者，当慎用栃子豉汤， 以防苦寒之品，更损中阳，如“若下之，必胸下结硬 。”13)，示人太阴虚寒证当温健中阳，若误将虚寒性腹 满痛作阳明腑实证，而用寒凉攻下，则变生它证。甚至 对妇人热入血室证，恐将“暮则垥语”之证作阳明之热实 论治，故告之日“无犯胃气及上下二焦。”14)。而桂枝 加大黄汤之用，仲景惟恐过用苦寒，重伤来复之脾阳， 故示人“宜减之，以其人胃气弱，易动故也。”。下利 清谷，不可攻表，汗出必胀满。”15)，示人中阳已虚 者，不可妄用祛邪之法，以免变生它病。

\section{4）煎服调护，顾护脾胃}

在药的煎法、服法及药后调护中仍可体会到仲景用

12）熊曼琪. 伤寒论. 北京. 人民卫生出版社. 2000. p.197.

13）熊曼琪. 伤寒论. 北京. 人民卫生出版社. 2000. p.541.

14）熊曼琪. 伤寒论. 北京. 人民卫生出版社. 2000. p.541.

15）熊曼琪. 伤寒论. 北京. 人民卫生出版社. 2000. p.752. 
药之妙、立意之深远. 如大黄黄连泻心汤, 所用药物多 属苦寒之品, 过用则有伤阳败胃之弊, 故仲景在煎服法 中云“麻沸汤二升渍之”，此渍而不煎，乃取药轻清之气 而不用其味, 既达到治疗目的又可避免苦寒伤中之弊。 桂枝汤服法“服已须舆，嗓热稀䉼一升余，以助药力”16), 药后啜弹不仅助汗源, 也包含着温养脾胃之气, 以防汗后 伤正之意。三物白散治寒实结胸证, 但白散药性峻猛, 易伤中气, 故方后曰“以白七饮和服”及“不利, 进热䉼一 杯, 利过不止, 进冷弹一杯。”。此即用白米汤缓和药之 毒性，顾护脾胃，同时为了加强或抑制泻下作用亦用热 弹或冷粥调节，其目的都是借水谷以保胃气存津液。十 東汤是以甘遂、芫花为主峻逐水饮, 仲景以肥大東十枚 煎汤取汁送服, 以补脾胃扶助正气, 并缓和诸药毒性。 另“得快下后, 糜䉼自养。”则强调了中病即止, 并借糜 粥以养正气，使邪去而正不伤。此仲景立法之尽善也。 而大承气汤云“分温再服, 得下, 余勿服。”小承气汤云 “分温二服, 初服汤当更衣不尔者尽之, 若更衣者勿服 之。”17)，同样示人中病即止不可过伐。

\section{5）胃气为本, 预后变化}

仲景不但以脾胃的盛衰别证候, 定治则, 制方药, 而且还通过审察脾胃之强弱虚实, 来判断预后的吉凶, 脾胃由衰而盛则正气复, 病可向愈; 脾胃由衰而败则正 气随之衰败, 预后多危。如“……虽暴烦下利日十余 行, 必自止, 以脾家实, 腐秽当去也。” 症见暴烦下 利, 乃知脾阳来复, 则水湿得运, 腐秽当去, 故断为向 愈之机。而“伤寒发热, 下利至甚, 厥不止者, 死。”, 则表明脾胃阳气亡失, 内无温运而利不止，外无温煦而 厥不还, 阳气已难回复, 阴竭阳绝, 故属危候。再如 “……㕅厥利者, 当不能食; 今反能食者, 恐为除中。 食以素饼，不发热者，知胃气尚在，必愈。”“腹中应 冷, 当不能食, 今反能食, 此为除中, 必死。”18)这两条 均为病至厥阴, 为六经传变的最后危重阶段, 但邪气相 争的成败䏌键取决于脾胃之气的存亡, 前者通过饮食试 验，可知胃气尚存，而断为必愈，后者见腹中冷，不能

16）熊曼琪. 伤寒论. 北京. 人民卫生出版社. 2000. p.39.

17）尤在㳗. 伤寒贯珠集. 北京. 中国中医药出版社. 2008. p.30.

18）陈修园. 伤寒论浅注. 福建科学技术出版社. 1987. p.142.
饮食, 则为胃气伤败, 故成必死之局。

\section{6）病㽿调理, 继培后天}

仲景注重脾胃的学术思想还体现在痓后仍不忘调理 脾胃, 诚为“脾胃为气血升化之源, 后天之本。”理论的 实践者. 提出“病人脉以解，而日暮则微烦，以新病痏， 人强与谷，脾胃尚弱，不能消谷，故令微烦，损谷则 愈”, 说明久病初愈, 胃气新复, 虽有轻微不适, 应尽量 勿服药汁, 以免损伤初复之胃气，调整饮食，胃复则 愈。不仅如此, 仲景还在专篇㽿后劳复中, 设立调治中 焦之法, 如痏后虚寒喜唾证, 予理中丸以温中散寒 ; 痏 后劳复证，予以枳实枚子豉汤，以下气除烦，畅复胃 气; 痕后发热证, 则予以小柴胡汤和之, 以调复胃气。

\section{III. 結 論}

张仲景十分重视脾胃，顾护脾胃的思想在其著作『伤 寒杂病论』中有着非常丰富的内容和十分广泛的运用。 『内经』为脾胃学说尊定了基础, 『伤寒杂病论』继承和发 展了『内经』的思想，它是对『内经』理论的发扬光大和具 体实践，并将理论与临床实践相结合，在脾胃学说的发 展中，起到了承上启下的作用。从辨证、用药、调护等 多方面注重脾胃的功能的发挥, 对后世产生重大影响。 脾胃学说中医理论之瑰宝，值得大家继承深入的研究与 实践。

\section{致 谢}

研究经费由韩国圆光Digital大学赞助(2012年课题 经费)

\section{參考文獻}

1. 黄贵华. 张仲景脾胃学说研究概况. 广西中医学 院学报. 2006. 9(4). pp.70-72.

2. 丁文君, 张瀚元, 王柳明。『金匾要略』治未病之 管窥. 吉林中医药. 2009. 29(3). pp.269-270.

3. 孙国中, 方向红校注. 重广补注黄帝内经素问. 北 京. 学苑出版社. 2004. p.19.

4. 陈纪. 金贵要略. 北京. 人民卫生出版社. 2000. p.36. 
5. 熊曼琪. 伤寒论. 北京. 人民卫生出版社. 2000.

p.16, 39, 162, 197, 444, 533, 539, 541, 556, 752 .

6. 尤在泾. 伤寒贯珠集. 北京. 中国中医药出版社. 2008. p.30.

7. 陈修园. 伤寒论浅注. 福建科学技术出版社.

1987. p.142. 